\title{
LEVELS OF ARGININE-VASOPRESSIN IN CEREBROSPINAL FLUID DURING PASSIVE AVOIDANCE BEHAVIOR IN RATS
}

\author{
F. Laczi, 0. Gaffori, M. Fekete**, E.R. de Kloet ${ }^{\circ}$ \\ \& \\ D. de Wied \\ Rudolf Magnus Institute for Pharmacology, Medical Faculty, \\ University of Utrecht, Vondellaan 6, 3521 GD Utrecht, \\ The Netherlands
}

(Received in final form March 28, 1984)

Summary

The concentration of immunoreactive arginine-vasopressin (IR-AVP) was measured in the cerebrospinal fluid (CSF) during acquisition and retention of passive avoidance behavior. IR-AVP level in CSF of male Wistar rats immediately after the learning trial was increased; the rate of which was related to the intensity of the electric footschock during the learning trial and the avoidance latency. as measured 1 day after the learning trial. Immediately after the $24 \mathrm{~h}$ retention test IR-AVP levels were significantly increased in rats subjected to the low $(0.25 \mathrm{~mA})$ shock intensity during the learning trial, but IR-AVP levels of rats exposed to the high shock $(1.0 \mathrm{~mA})$ were under the limit of detection. If the retention test was postponed till 5 days after the learning trial, the increase of IR-AVP level in the CSF was related to avoidance latencies which reflect the intensity of aversive stimulation (electric footshock). The results suggest an association between central AVP release and passive avoidance behavior and may be indicative of the role of this peptide in neuronal mechanisms underlying learning and memory processes.

The neurohypophyseal hormone arginine-vasopress in (AVP) modulates memory processes (1). Administration of AVP and related peptides increases resistance to extinction of active avoidance behavior, facilitates retention of passive avoidance behavior and prevents or reverses experimental amnesia. Intracerebroventricular (i.c.v.) administration of AVP induces similar effects in much lower doses than after peripheral administration. Furthermore, i.c.v. but not peripheral injection of AVP antiserum induces a marked deficit in passive avoidance performance. These results suggest that central rather than peripheral release of AVP is involved in learning and memory processes (2). Studies on the site of action of AVP on avoidance behavior revealed that midbrainlimbic structures are involved in the memory effect of the peptide (3). Putative AVP receptor sites have been demonstrated in discrete areas of the 1 imbic brain (4-9), that may mediate the memory enhancing effects of AVP.

* On leave of absence from the Endocrine Unit and Research Laboratory, First Department of Medicine, University Medical School, Szeged, Hungary.

$\star \star 0$ n leave of absence from the Department of Pathophysiology, University

Medical School, Szeged, Hungary.

-To whom correspondence should be sent. 
In recent experiments we have measured the IR-AVP content of limbic regions during passive avoidance behavior. It was found that at the $24 \mathrm{~h}$ retention test the IR-AVP content was reduced in the lateral septum, hippocampus as well as in the paraventricular and suprachiasmatic nucleus, while it was increased in the central amygdala nucleus (10). In subsequent experiments in which the studies were focussed on the hippocampus and amygdala, we observed a depletion of IR-AVP in hippocampus immediately after the $1.0 \mathrm{~mA}$ electric footshock and at the 24 and $120 \mathrm{~h}$ retention test only in those animals which showed passive avoidance behavior (11).

AVP can be detected with a radioimmunoassay in the CSF (12) and in CSF the IR-AVP levels show circadian variation (13). It was deemed of interest to know whether AVP levels in the CSF would reflect the activity of the central vasopressin system in response to passive avoidance behavior, which is markedly affected by vasopressin. Therefore, IR-AVP levels were measured in CSF of rats immediately after the learning trial of a passive avoidance response and at 24 and $120 \mathrm{~h}$ after the learning trial, when CSF was taken immediately after the retention test. The results indicate that under certain conditions the activity of the vasopressin system can be read from the levels of AVP in the CSF.

\section{Materials and Methods}

Animals and surgery

Male rats of a Wistar strain weighing $180-200 \mathrm{~g}$ at the onset of the experiment were used. The rats were housed in separate cages and had free access to water and food. The animal house was illuminated from $6 \mathrm{a} . \mathrm{m}$. to $8 \mathrm{p.m}$. They were transported to the experimental room $1 \mathrm{~h}$ before the experiment. Al1 observations were made between $1 \mathrm{p} . \mathrm{m}$. and $4 \mathrm{p.m}$. A permanent stainless steel cannula was implanted in the cisterna magna enabling the withdrawal of CSF from free moving animals (14).

\section{Passive avoidance behavior}

The passive avoidance procedure was adapted from Ader et al. (15). The experimental apparatus consisted of an illuminated platform attached to a dark compartment equipped with a grid floor. After habituation to the dark compartment $(2 \mathrm{~min})$ rats were placed on the platform and allowed to enter the dark compartment. Since rats prefer dark to light, they normally enter within 15 s. On the next day, after three more adaptation trials (intertrial interval $5 \mathrm{~min}$ ) an unavoidable footshock (with a duration of $3 \mathrm{~s}$ ) was delivered through the grid floor of the dark compartment (learning trial). Three different shock intensities were applied, $0.00,0.25$ and $1.00 \mathrm{~mA}$. Rats were removed from the box $10 \mathrm{~s}$ after the termination of the shock. Passive avoidance latencies were tested at retention trials performed at either 24 or $120 \mathrm{~h}$ after the learning trial; the rat was placed on the platform and the latency to enter the dark compartment was measured up to a maximum of $300 \mathrm{~s}$.

\section{CSF collection and AVP radioimmunoassay procedure}

The CSF was collected in 3 different situations: at $30 \mathrm{~s}$ after the learning trial and at $30 \mathrm{~s}$ after the $24 \mathrm{~h}$ and the $120 \mathrm{~h}$ retention test. Although anesthesia is not necessary to obtain CSF from the cisterna magna, this procedure was chosen in order to compare the results with those obtained in experiments in which eye plexus blood was collected under ether anesthesia (16). Samples of CSF were collected in cooled polypropylene tubes. These were centrifuged at $4^{\circ} \mathrm{C}$ in order to remove blood contamination. For the determination of IRAVP in CSF, samples obtained from two animals with a similar passive avoid- 
ance response were pooled. The total CSF volume was $150 \mu 1$. The pooled samples were lyophilised. AVP determinations were performed in unextracted, lyophilised samples using a specific RIA system. Immediately before the RIA procedure the lyophilised CSF samples were redissolved in assay buffer. The antiserum used was highly specific for AVP, the cross-reactivity on a mol basis with oxytocin being $0.0019 \%$ and with vasotocin $0.25 \%$. Synthetic AVP (pressor activity: 509 IU/mg, Organon, 0ss, The Netherlands) was used as a standard and for preparation of the tracer. In a previous study using the same antiserum a good correlation was found between antidiuretic activity and immunoreactivity of an AVP sample extracted from eye plexus blood plasma (16).

For dilution of standard and CSF samples, veronal buffer ( $\mathrm{pH} 8.0$ ) containing $0.02 \mathrm{M}$ barbituric acid (Merck, Darmstadt, Germany), $66.6 \mathrm{nmol} / \mathrm{ml} \mathrm{L}$ cystine (Nutr. Biochem. Comp. Cleveland, USA), 0.01 EDTA (Merck) and $73.5 \mathrm{nmol} / \mathrm{ml}$ human serum albumin (HSA, Sigma, Brunschwig Chemie, Ansterdam, The Netherlands) was used. Antiserum was diluted with the same buffer containing $18.4 \mathrm{nmol} / \mathrm{ml}$ HSA. The incubation mixture typically consisted of $50 \mu 1$ AVP antiserum (final dilution $1: 32,000), 50 \mu 1$ standard or sample and $10 \mu 1$ 125I iodo AVP in veronal buffer. Assays were performed in an equilibrium system. The tubes were incubated at $4^{\circ} \mathrm{C}$ for $72 \mathrm{~h}$. Bound AVP was separated from free by addition of $100 \mu l$ of dextran coated charcoal. AVP levels were expressed in $\mathrm{fmol} / \mathrm{ml}$ CSF. All experiments were performed using a blind procedure where the experimenter performing the RIA determination was unaware of the behavioral performance of the rat from which the CSF was collected. IR-AVP levels in CSF and passive avoidance latencies were analyzed with ANOVA-testing (Kruskal-Wallis) and subsequently with Mann-Whitney non-parametric tests.

\section{Results}

Figure 1 presents two standard curves that were prepared in veronal buffer containing $73.5 \mathrm{nmol} / \mathrm{ml}$ HSA or human CSF, respectively. The latter samples were lyophilised and redissolved in veronal buffer. This procedure caused a slight depression in the binding, however, it changed neither the slope of the standard curve nor the sensitivity of the assay. One rat CSF sample with an AVP concentration of about $65 \mathrm{fmol} / \mathrm{ml}$ was lyophilised and subsequently diluted serially with assay buffer, and AVP was measured. The values obtained parallelled the standard curve (Fig. 1). Therefore, and in view of the specificity of the antiserum, it is likely that the material measured in CSF is immunologically indistinguishable from AVP. The effect of shock intensities on IR-AVP levels of CSF and passive avoidance latency scores of rats are shown in Table 1. The $24 \mathrm{~h}$ avoidance latencies of each group of rats exposed to electric footshocks of different intensity differed significantly from those of the non-shocked animals. The retention latencies in each group of animals were related to the intensity of the electric footshock applied at the learning trial. The higher the intensity of the electric footshock at the learning trial, the higher the passive avoidance scores at the retention sessions. At $120 \mathrm{~h}$ after the learning trial the response latencies were slightly lower than those found at the $24 \mathrm{~h}$ retention test, but the latencies were still significantly different from those found in the non-shocked group.

Rats that were exposed to the $0.25 \mathrm{~mA}$ of shock intensity showed a tendency to increase their IR-AVP levels in the CSF at $30 \mathrm{~s}$ after the learning trial. The high shock intensity (1.0 mA) caused a significant elevation in IR-AVP levels in CSF $(p<0.01)$. CSF IR-AVP levels were increased significantly 24 $h$ after the learning trial (retention session) in rats subjected to the footshock of low intensity $(0.25 \mathrm{~mA})$ during the learning trial but were below the detection limit after $1.00 \mathrm{~mA}$. The IR-AVP levels in CSF of non-shocked animals at $120 \mathrm{~h}$ after the learning trial did not significantly differ from those found in CSF samples collected at $30 \mathrm{~s}$ after the learning trial or at 


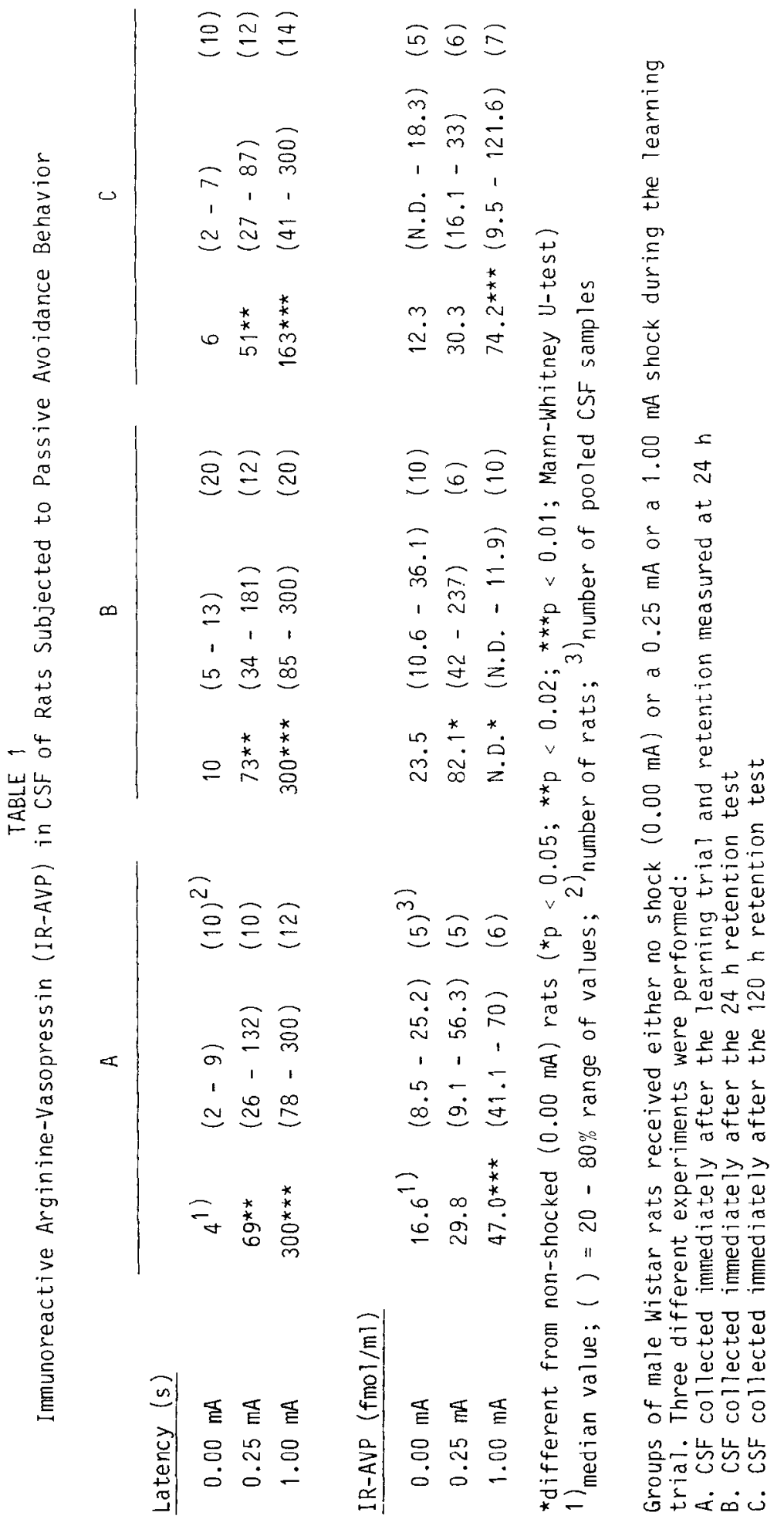




\section{$\mathrm{B} / \mathrm{B}_{\circ} \%$}

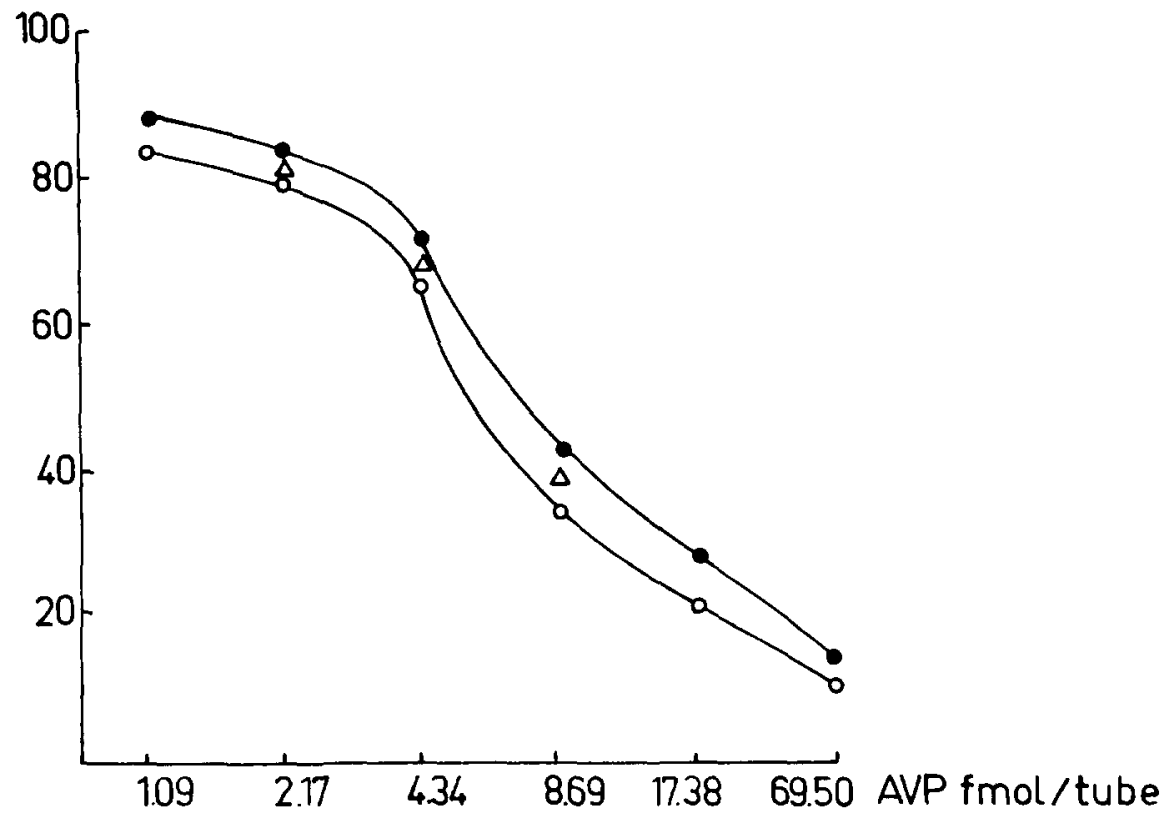

FIG. 1

Standard curves obtained using rabbit antiserum in a $1: 32,000$ final dilution, one in buffer containing $73.53 \mathrm{nmol} / \mathrm{ml}$ of human serum albumin (HSA) ——, one in human CSF subsequently lyophylised and redissolved in buffer containing $73.53 \mathrm{nmol} / \mathrm{ml}$ of HSA 0-0. Triangles $(\Delta)$ indicate the values of serial dilutions of lyophilised rat CSF.

the $24 \mathrm{~h}$ retention test. CSF IR-AVP levels of rats exposed during the learning trial 5 days previously to $10 \mathrm{w}(0.25 \mathrm{~mA})$ or high $(1.0 \mathrm{~mA})$ footshock were significantly increased, the magnitude of which depended on the intensity of the footshock.

\section{Discussion}

The present data show changes in the level of IR-AVP in CSF immediately after learning and retention of a passive avoidance response. After the learning trial IR-AVP levels increase in the CSF and the magnitude corresponds with the intensity of the electric footshock during the learning trial. Retention of passive avoidance behavior is associated with an increase in AVP level in CSF of rats tested 5 days after the learning trial; the AVP level being related to the avoidance latencies which reflect the intensity of the aversive stimulation.

A more complex pattern of AVP release in the CSF appeared when AVP levels were studied immediately after the $24 \mathrm{~h}$ retention test. While a previously experienced moderate footshock $(0.25 \mathrm{~mA})$ increased IR-AVP levels in the CSF, the levels were not detectable in the CSF of rats exposed to high shock (1.0 
$\mathrm{mA}$ ) at the learning trial. This is not easy to explain but it may be that exposure to high shock intensity at the learning trial releases most of the readily releasable pool of AVP from the extrahypothalamic AVP containing nerve terminals. Repletion of AVP released from terminals after the $1.0 \mathrm{~mA}$ shock may not be complete in the subsequent $24 \mathrm{~h}$ interval, but needs more time, since increased IR-AVP levels were found aga in at the retention test, 5 days after the learning trial. Therefore, the depleted stores of AVP in nerve terminals would not permit release of measurable amounts of IR-AVP into the CSF at the $24 \mathrm{~h}$ retention test. This hypothesis, however, assumes that the amount of IR-AVP at the site of action in the brain would still be sufficient to affect passive avoidance behavior. That such locally released AVP is effective may be concluded from experiments showing that local administration of AVP antiserum in the brain target sites at the $24 \mathrm{~h}$ retention test blocks passive avoidance behavior (17).

The line of reasoning followed in the interpretation of changes in IR-AVP levels in CSF finds support from more recent data showing that marked depletion of IR-AVP takes place in limbic structures immediately after the learning trial (11). IR-AVP levels in hippocampus, septum, the paraventricular and suprachiasmatic nucleus are also reduced at the $24 \mathrm{~h}$ retention test in rats exposed to the high shock. of $1.0 \mathrm{~mA}(10,11)$ which is associated with the non-detectable IR-AVP in the CSF. The reduction in tissue levels of IR-AVP may reflect an increased secretory activity at the AVP terminal. The increase of the IR-AVP level in the CSF may, therefore, be an index of such secretory activity provided, however, that mild shock conditions are applied or that a peptidergic terminal is permitted enough time to replete its readily releasable pool. Further support for this line of reasoning may be taken from the reported circadian variation of AVP levels in the CSF $(13,18)$, which also suggests that this level reflects the activity of central AVP secretory neurones. Moreover, memory processes also are subject to circadian organization (19). The significance of AVP released into the liquor is not clear. It could represent the actual spill-over of released AVP as mentioned above, or the CSF may be used as avenue of transport for AVP to reach a distant site of action in the brain (20-22).

Mens et al. (21) did not find significant changes in CSF IR-AVP level during passive avoidance behavior. A possible explanation for the difference between these and the present data may be the difference in experimental procedure and the RIA determination. We arrived at this conclusion after examination of the influence of various experimental conditions on the IR-AVP content of the hippocampus. Exposure to a novel environment is a potent stimulus for depletion of hippocampal IR-AVP. Changes in tissue IR-AVP were, therefore, only detectable during passive avoidance behavior, when the animals were previously handled and habituated to the conditions of the behavioral experiment (11). Such precautions were also taken in this study.

The changes in IR-AVP level of CSF might have been due to cleavage of AVP in smaller fragments. CSF is virtually devoid of proteolytic enzymes involved in peptide conversion (23). Burbach et a T. (24) showed that brain synaptic membranes contained an amino peptidase that cleaves the ring portion of the molecule at the Cys 1 and Tyr2 bond, and generates a series of C-terminal fragments, that also occur endogenously in the brain (25). Two fragments, the $\left[p G l u 4, C y t^{6}\right]$ AVP-(4-9) and its desglycinamide derivative were at least one thousand times more potent than AVP-(1-9) in facilitation of a passive avoidance response (24). However, using an antiserum that showed an approximate $30 \%$ cross-reactivity for the $\left[\mathrm{pG} 1 \mathrm{u}^{4}, \mathrm{Cyt}^{-}\right]$AVP-(4-9) fragment essentially the same patterns of changes in IR-AVP leve] of CSF were found during passive avoidance behavior (26). Therefore, altered biotransformation of AVP in the brain may contribute to, but certainiy 
does not explain the profound changes in IR-AVP level of CSF during passive avoidance behavior.

In conclusion, the present study suggests that performance of a passive avoidance response is under certain conditions associated with the release of AVP in the CSF. This finding may be of assistance in the understanding of the role of this peptide in brain mechanisms underlying learning and memory processes.

\section{References}

1. D. DE WIED, Proc. Roy. Soc. Lond. B. 210 183.194 (1980).

2. TJ.B. VAN WIMERSMA GREIDANUS, J.M. VAN REE and D. DE WIED, Pharmacol. Ther. 20 437-458 (1983).

3. G.L. KOVACS, B. BOHUS, D.H.G. VERSTEEG, E.R. DE KLOET and D. DE WIED, Brain Res. 175 303-314 (1979).

4. D.G. BASKIN, F. PETRACCA and D.M. DORSA, Eur. J. Pharmacol. 90 155-158 (1983).

5. H.I. YAMAMURA, K.W. GEE, R.E. BRINTON, TH.P. DAVIS, M. MADLEY and J.K. WAMSLEY, Life SCi. 32 1919-1924 (1983).

6. F.W. VAN LEEUWEN and P. WOLTERS, Neurosci. Lett. 41 61-66 (1983).

7. A.F. PEARLMUTter, M.G. CONSTANT INI and B. LOESER, Peptides 4 335-341 (1983)

8. C. BARBERIS, FEBS 162 400-405 (1983).

9. A. BIEGON, E.R. DE KLOET, TH.D. VOORHUIS and M. TERLOU, Neurosci. Lett. 44 229-234 (1984).

10. F. LACZI, 0. GAFFORI, E.R. DE KLOET and D. DE WIED, Brain Res. $260342-$ $346(1983)$.

11. F. LACZI, 0. GAFFORI, E.R. DE KLOET and D. DE WIED, Brain Res. 2:0. 30s$315(1983)$.

12. T,G. LUERSSEN and G.L. ROBERTSON, Neurobiology of Cerebrospinal Fluid, Vol. 1, Ed. J.H. Wood, pp. 613-621, PTenum Press, New York (1980).

13. W.J. SCHWARTZ, R.J. COLEMAN and S.M. REPPERT, Brain Res. 263 105-112 (1983).

14. H.M. BOUMAN and TJ.B. VAN WIMERSMA GREIDANUS, Brain Res, Bul1. 4 575577 (1979).

15. R. ADER, J.A.W.M. WEIJNEN and P. MOLEMAN, Psychon. Sci. 26 125-128 (1972).

16. F. LACZI, M. FEKETE and D. DE WIED, Life Sci. 32 577-589 (1983).

17. G.L. KOVACS, R.M. BUIJS, B. BOHUS and TJ.B. VAN WIMERSMA GREIDANUS, Physiol. Behav. 28 45-48 (1982).

18. M.J. PERLOW, S.M. REPPERT, H.A. ARTMAN, D.A. FISHER, S.M. SEIF and A.G. ROBINSON, Science 216 1416-1418 (1982).

19. W.N. TAPP and F.A. HOLLOWAY, Science 211 1056-1058 (1981).

20. E.R. DE KLOET, M. PALKOVITS and E. MEZEY, Pharmacol. Ther. 12 321-357 (1981).

21. W.B.J. MENS, M.A.H. VAN EGMOND, A.A. DE ROTTE and TJ.B. VAN WIMERSMA GREIDANUS, Horm. Behav. 16 371-382 (1982).

22. E.M. RODRIQUEZ, J. Endocrino 1. $71407-443$ (1976).

23. J.P.H. BURBACH, J.G. LOEBE?, J. VERHOEF, E.R. DE KLOET, J.M. VAN REE and ¿. DE WIED, Lancet II 480-481 (1979).

24. J.P.H. BURBACH, G.L. KOVACS, D. DE WIED, J.W. VAN NISPEN and H.M. GREVEN Science 221 1310-1312 (1983).

25. J.P.H. BURBACH, X-C. WANG, J.A. TEN HAAF and D. DE WIED, brain kes. in press.

26. J.A. TEN HAAF, F. LACZI, 0. GAFFORI, H.D. VELDHUIS, TJ.B. VAN WIMERSMA GREIDANUS and D. DE WIED. Pharmac. Weekb1. Sci. Ed. 5267 (1983). 